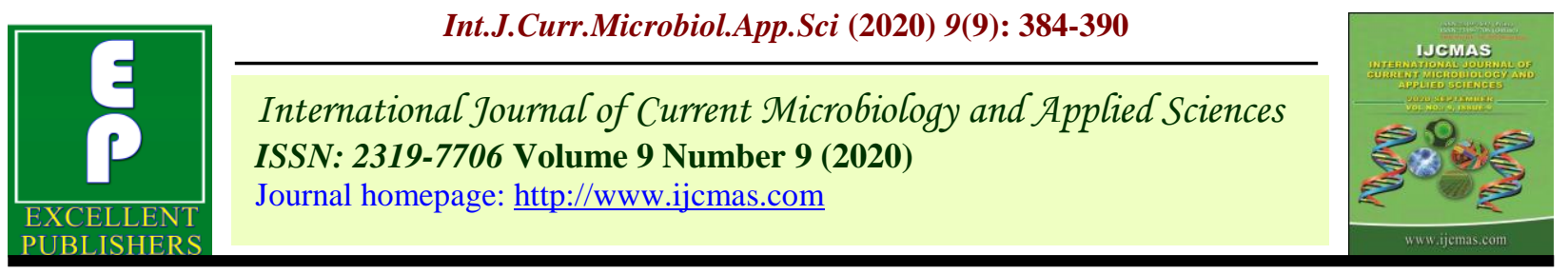

Original Research Article

https://doi.org/10.20546/ijcmas.2020.909.048

\title{
Developmental Assessment Status of Young Children in Agrarian Families of Telangana State, India
}

\author{
V. Kavitha Kiran and K. Yashoda* \\ All India Coordinated Research Project on Home Science, Human Development Component, \\ PGRC, PJTSAU, Rajendranagar, Hyderabad-30, India \\ *Corresponding author
}

\section{A B S T R A C T}

Keywords

Developmental Assessment, Young Children, Agrarian Families

\section{Article Info}

Accepted:

04 August 2020

Available Online:

10 September 2020
The objective was Developmental assessment status of Children in Agrarian families. A sample consisted of 150 couples (fathers and mothers) i.e. 300 parents having children below 5 yrs, Selected randomly. Results concluded that With regard to Physical \& Motor Development $46 \%$ were in average developmental status, 30\% exhibited good developmental status and only $24 \%$ showed poor developmental status. With regard to Sensory, Perceptual \& Cognitive Development only $20 \%$ showed good developmental status. Only $18 \%$ showed good developmental status in Language, Literacy \& Communication Development.22\% showed poor developmental status in Personal -Social \& Emotional Development and $18 \%$ showed good developmental status in Creativity.

\section{Introduction}

Physical development goes hand-in-hand with cognitive development in young children, and progress in one domain often relies on progress in the other. Similar to cognitive development, typical physical development follows a common trajectory among children but with individual differences in the rate of development. A child's physical development encompasses healthy physical growth; the development of sensory systems, including vision and hearing; and development of the ability to use the musculoskeletal system for gross motor skills that involve large body movements as well as fine motor skills that require precision and the controlled production of sound for speaking. Sensory and motor development are critical for both everyday and classroom activities that contribute to cognitive development, early learning, and eventually academic achievement.

Young children's growth in gross and fine motor skills develops throughout the birth through age 8 continuum-early on from holding their head up; rolling over; standing, crawling, and walking; to grasping cereal, picking up blocks, using a fork, tying 
shoelaces, and writing. A number of recent studies have focused on the relationships among the development of fine and gross motor skills in infants and young children, cognitive development, and school readiness. For example, one study found that students showing deficiencies in fine motor skills exhibited lower math and verbal scores (Sandler et al., 1992), and more recent studies have also shown that fine motor skills were strongly linked to later achievement (Grissmer et al., 2010a; Pagani and Messier, 2012). Some of the same neural infrastructure in the brain that controls the learning process during motor development are also involved in the control of learning in cognitive development (Grissmer et al., 2010a). The evidence of the impact of motor skills on cognitive development and readiness for school calls for a shift in curricula to include activities that focus on fine motor skills, to include the arts, physical education, and play (Grissmer et al., 2010b).

Child development and early learning are closely intertwined with child health. Indeed, each is a foundation for outcomes in the other: health is a foundation for learning, while education is a determinant of health (Zimmerman and Woolf, 2014). The Center on the Developing Child at Harvard University (2010) has described three foundational areas of child health and development that contribute to physical and mental well-being:

Stable and responsive relationships - such relationships provide young children with consistent, nurturing, and protective interactions with adults that enhance their learning and help them develop adaptive capacities that promote well-regulated stress response systems.

Safe and supportive physical, chemical, and built environments - such environments provide physical and emotional spaces that are free from toxins and fear, allow active exploration without significant risk of harm, and offer supports for families raising young children.

Sound and appropriate nutrition - such nutrition includes health-promoting food intake as well as eating habits, beginning with the future mother's nutritional status even before conception.

The preceding discussion makes clear that children's socioemotional health is linked to the socioemotional well-being of the adults in their lives. Consistent with the research on the social buffering of stress discussed earlier, when parents and other caregivers are managing well, they can help children cope more competently with the ordinary stresses that inevitably occur. When caregivers are stressed, by contrast, they cannot provide this buffering and are instead more often a source of stress for children. When parents are depressed, for example, they can be unpredictably sad, hostile, critical, and/or disengaged (NRC and IOM, 2009). This constellation of behaviors constitutes a difficult combination of threat and withdrawal of support for children. Young children with a depressed mother are more likely, therefore, to exhibit heightened stress reactivity to moderate challenges; to have an insecure attachment to the parent; to show lower levels of cognitive performance and, later, poorer academic achievement; and to be at greater risk of becoming depressed themselves.

It is difficult to think of any child developing language apart from social interactions with others. As discussed earlier in this chapter, variability in these experiences, beginning in infancy, helps account for socioeconomic disparities in language and mathematical skills that are apparent by the time children enter school. In a widely cited study, Hart and 
Risley (1995) recorded 1 hour of naturally occurring speech in the homes of 42 families at monthly intervals beginning when children were 7-9 months old and continuing until they turned 3 years. They found that by age 3, children living in the most socioeconomically advantaged families had a working vocabulary that was more than twice the size of that of children growing up in the most disadvantaged families. The latter group of children also was adding words more slowly than their advantaged counterparts. The differences in children's vocabulary size were associated, in part, with how many words were spoken to them during the home observations, with a much richer linguistic environment being characteristic of the most advantaged homes.

The development of social and emotional competence is an important part of child development and early learning. Socioemotional competence has been described as a multidimensional construct that contributes to the ability to understand and manage emotions and behavior; to make decisions and achieve goals; and to establish and maintain positive relationships, including feeling and showing empathy for others. Although their importance is widely recognized, universal agreement is lacking on how to categorize and define these areas of development. The Collaborative for Academic, Social, and Emotional Learning offers a summary construct with five interrelated groups of competencies that together encompass the areas typically considered to be part of socioemotional competence.

Socioemotional competence increasingly is viewed as important for a child's early school adjustment and for academic success at both the preschool and K-12 levels (Bierman et al., 2008a,b; Denham and Brown, 2010; Heckman et al., 2013; La Paro and Pianta, 2000; Leerkes et al., 2008). A growing body of research addresses the relationship between dimensions of socioemotional competence and cognitive and other skills related to early learning and later academic achievement (Bierman et al., 2008a,b; Graziano et al., 2007; Howse et al., 2003b; Miller et al., 2006). Socioemotional development early in life also increasingly is understood to be critically important for later mental wellbeing, and for contributing to subsequent mental health problems when there are enduring disturbances in socioemotional functions (IOM and NRC, 2009; Leckman and March, 2011).

Children's language development and literacy development are central to each other. The development of language and literacy includes knowledge and skills in such areas as vocabulary, syntax, grammar, phonological awareness, writing, reading, comprehension, and discourse skills. The following sections address the development of language and literacy skills, including the relationship between the two; the role of the languagelearning environment; socioeconomic disparities in early language environments; and language and literacy development in dual language learners.

\section{Materials and Methods}

Research Design: Quasi experimental design will be adopted through pre \&post single group study

Locale of the Study: Adopted villages of Maheshwaram Mandal, Ranga Reddy District will be covered for sample selection

Sampling Procedure: Sample will comprise of 150 couples (fathers and mothers) i.e. 300 parents having children below 5 yrs.

Tool: Developmental status of Children scale developed by AICRP- Human Development. The scale was tested for its reliability and 
validity and then administered to the sample. The table 1 depicts the Developmental assessment status of Children (3-4yrs) in 5 developmental areas.

With regard to Physical \& Motor Development, out of 50 children, $46 \%$ were in average developmental status, $30 \%$ exhibited good developmental status and only $24 \%$ showed poor developmental status.

With regard to Sensory, Perceptual \& Cognitive Development, out of 50 children, $42 \%$ were in average developmental status, $38 \%$ exhibited poor developmental status and only $20 \%$ showed good developmental status.

With regard to Language, Literacy \& Communication Development, out of 50 children, $44 \%$ were in poor developmental status, 38\% exhibited average developmental status and only $18 \%$ showed good developmental status.

With regard to Personal -Social \& Emotional
Development, out of 50 children, $40 \%$ were in average developmental status, $38 \%$ exhibited good developmental status and only $22 \%$ showed poor developmental status.

With regard to Creativity, out of 50 children, $42 \%$ were in poor developmental status, $40 \%$ exhibited average developmental status and only $18 \%$ showed good developmental status.

Over all, out of 50 children, $42 \%$ were in average developmental status, $30 \%$ exhibited poor developmental status and only $28 \%$ showed good developmental status.

The table 2 depicts the Developmental assessment status of Children (4 - 5yrs) in 5 developmental areas.

With regard to Physical \& Motor Development, out of 50 children, $46 \%$ were in average developmental status, $30 \%$ exhibited poor developmental status and only $24 \%$ showed good developmental status.

Table.1 Developmental assessment status of Children (3 -4yrs) N=50

\begin{tabular}{|c|c|c|c|c|}
\hline \multirow[t]{2}{*}{ S.NO } & \multirow[t]{2}{*}{ Area } & Poor DS: < 6 & $\begin{array}{l}\text { Average DS: } \\
6-12\end{array}$ & $\begin{array}{l}\text { Good DS: } \\
13-20\end{array}$ \\
\hline & & No \& $\%$ & No \& \% & No \& \% \\
\hline 1 & $\begin{array}{l}\text { Physical \& Motor Development ( } 5 \\
\text { Statements) }\end{array}$ & $12(24 \%)$ & $23(46 \%)$ & $15(30 \%)$ \\
\hline 2 & $\begin{array}{l}\text { Sensory, Perceptual \& Cognitive } \\
\text { Development ( } 5 \text { Statements) }\end{array}$ & $19(38 \%)$ & $21(42 \%)$ & $10(20 \%)$ \\
\hline 3 & $\begin{array}{l}\text { Language, Literacy \& } \\
\text { Communication ( } 5 \text { Statements) }\end{array}$ & $22(44 \%)$ & $19(38 \%)$ & $9(18 \%)$ \\
\hline 4 & $\begin{array}{l}\text { Personal -Social \& Emotional } \\
\text { Development ( } 5 \text { Statements) }\end{array}$ & $11(22 \%)$ & $20(40 \%)$ & $19(38 \%)$ \\
\hline 5 & Creativity (5 Statements) & $21(42 \%)$ & $20(40 \%)$ & $9(18 \%)$ \\
\hline & & $\begin{array}{l}\text { Poor DS: < } \\
33\end{array}$ & $\begin{array}{l}\text { Average DS: } \\
34-66\end{array}$ & $\begin{array}{l}\text { Good DS: } \\
67-100\end{array}$ \\
\hline & Over all & $15(30 \%)$ & $21(42 \%)$ & $14(28 \%)$ \\
\hline
\end{tabular}


Table.2 Developmental assessment status of Children (4-5yrs) N=50

\begin{tabular}{|l|l|c|c|c|}
\hline S.no & Area & Poor DS: < 6 & $\begin{array}{c}\text { Average DS: } \\
\text { 6-12 }\end{array}$ & $\begin{array}{c}\text { Good DS: } \\
\mathbf{1 3 - 2 0}\end{array}$ \\
\cline { 3 - 5 } & $\begin{array}{c}\text { No \& } \% \\
\text { No \& \% }\end{array}$ & No \& \% \\
\hline $\mathbf{1}$ & $\begin{array}{l}\text { Physical \& Motor Development } \\
\text { (5 Statements) }\end{array}$ & $\begin{array}{c}15(30 \%) \\
23(46 \%)\end{array}$ & $12(24 \%)$ \\
\hline $\mathbf{2}$ & $\begin{array}{l}\text { Sensory, Perceptual \& Cognitive } \\
\text { Development (5 Statements) }\end{array}$ & $19(38 \%)$ & $20(40 \%)$ & $11(22 \%)$ \\
\hline $\mathbf{3}$ & $\begin{array}{l}\text { Language, Literacy \& } \\
\text { Communication (5 Statements) }\end{array}$ & $21(42 \%)$ & $20(40 \%)$ & $9(18 \%)$ \\
\hline $\mathbf{4}$ & $\begin{array}{l}\text { Personal -Social \& Emotional } \\
\text { Development (5 Statements) }\end{array}$ & $12(24 \%)$ & $18(36 \%)$ & $20(40 \%)$ \\
\hline $\mathbf{5}$ & Creativity (5 Statements) & $23(46 \%)$ & $18(36 \%)$ & $9(18 \%)$ \\
\hline & & Poor DS: & Average DS: & Good DS: \\
& Total & $18(36 \%)$ & $20(40 \%)$ & $12(24 \%)$ \\
\hline
\end{tabular}

Table.3 Developmental assessment status of Children (5-6yrs) N=50

\begin{tabular}{|l|l|c|c|c|}
\hline S.no & Area & $\begin{array}{c}\text { Poor DS: } \\
\text { No \& } \%\end{array}$ & $\begin{array}{c}\text { Average } \\
\text { DS: 6- 12 } \\
\text { No \& \% }\end{array}$ & $\begin{array}{c}\text { Good DS: } \\
\mathbf{1 3 - 2 0} \\
\text { No \& \% }\end{array}$ \\
\hline $\mathbf{1}$ & $\begin{array}{l}\text { Physical \& Motor Development } \\
\text { (5 Statements) }\end{array}$ & $10(20 \%)$ & $22(44 \%)$ & $18(36 \%)$ \\
\hline $\mathbf{2}$ & $\begin{array}{l}\text { Sensory, Perceptual \& Cognitive } \\
\text { Development (5 Statements) }\end{array}$ & $19(38 \%)$ & $21(42 \%)$ & $10(20 \%)$ \\
\hline $\mathbf{3}$ & $\begin{array}{l}\text { Language, Literacy \& } \\
\text { Communication (5 Statements) }\end{array}$ & $20(40 \%)$ & $19(38 \%)$ & $11(22 \%)$ \\
\hline $\mathbf{4}$ & $\begin{array}{l}\text { Personal -Social \& Emotional } \\
\text { Development (5 Statements) }\end{array}$ & $10(20 \%)$ & $19(38 \%)$ & $21(42 \%)$ \\
\hline $\mathbf{5}$ & Creativity (5 Statements) & $20(40 \%)$ & $20(40 \%)$ & $10(20 \%)$ \\
\hline & Poor DS: & Average & Good DS: \\
\hline & Total & $16(32 \%)$ & $20(40 \%)$ & $14(28 \%)$ \\
\hline
\end{tabular}

*DS - Developmental status

With regard to Sensory, Perceptual \& Cognitive Development, out of 50 children, $40 \%$ were in average developmental status, $38 \%$ exhibited poor developmental status and only $22 \%$ showed good developmental status.

With regard to Language, Literacy \& Communication Development, out of 50 children, $42 \%$ were in poor developmental status, $40 \%$ exhibited average developmental status and only $18 \%$ showed good developmental status.

With regard to Personal -Social \& Emotional Development, out of 50 children, $40 \%$ exhibited good developmental status, $36 \%$ 
showed average developmental status and only $24 \%$ showed poor developmental status.

With regard to Creativity, out of 50 children, $46 \%$ were in poor developmental status, $36 \%$ exhibited average developmental status and only $18 \%$ showed good developmental status.

Over all, out of 50 children, $40 \%$ were in average developmental status, $36 \%$ exhibited poor developmental status and only $24 \%$ showed good developmental status.

The table 3 depicts the Developmental assessment status of Children (5 - 6yrs) in 5 developmental areas.

With regard to Physical \& Motor Development, out of 50 children, $44 \%$ were in average developmental status, $36 \%$ exhibited good developmental status and only $20 \%$ showed poor developmental status.

With regard to Sensory, Perceptual \& Cognitive Development, out of 50 children, $42 \%$ were in average developmental status, $38 \%$ exhibited poor developmental status and only $20 \%$ showed good developmental status.

With regard to Language, Literacy \& Communication Development, out of 50 children, $40 \%$ were in poor developmental status, 38\% exhibited average developmental status and only $22 \%$ showed good developmental status.

With regard to Personal -Social \& Emotional Development, out of 50 children, $42 \%$ exhibited good developmental status, 38\% showed average developmental status and only $20 \%$ showed poor developmental status.

With regard to Creativity, out of 50 children, $40 \%$ were in poor developmental status, $40 \%$ exhibited average developmental status and only $20 \%$ showed good developmental status.
Over all, out of 50 children, $40 \%$ were in average developmental status, 32\% exhibited poor developmental status and only $28 \%$ showed good developmental status.

In conclusion based on the bench mark issues and pre assessment results, videos, brochures, leaflets, resource books and educational posters were planned / developed on Developmental status of young children. Educational posters mainly focused on: Developmental status of young children age wise (3-4yrs,4-5Yrs,5-6Yrs) and Developmental wise such as Physical \& Motor Development, Sensory, Perceptual \& Cognitive Development, Language, Literacy \& Communication Development, Personal Social \& Emotional Development and Creativity.

\section{References}

Bierman KL, Domitrovich CE, Nix RL, Gest SD, Welsh JA, Greenberg MT, Blair C, Nelson KE, Gill S. Promoting academic and social-emotional school readiness: The Head Start REDI program. Child Development. 2008b; 79(6): 18021817.

Bierman KL, Nix RL, Greenberg MT, Blair C, Domitrovich CE. Executive functions and school readiness intervention: Impact, moderation, and mediation in the Head Start REDI program. Development and Psychopathology. 2008a; 20(3): 821-843.

Center on the Developing Child at Harvard University. The foundations of lifelong health are built in early childhood. 2010. [January 22, 2015]. http://www .developingchild.harvard.edu.

Denham SA, Brown C. "Plays nice with others": Social-emotional learning and academic success. Early Education and Development. 2010;21(5):652-680.

Graziano PA, Reavis RD, Keane SP, Calkins $\mathrm{SD}$. The role of emotion regulation and children's early academic success. 
Journal of School Psychology. 2007;45(1):3-19.

Grissmer D, Grimm KJ, Aiyer SM, Murrah WM, Steele JS. Fine motor skills and early comprehension of the world: Two new school readiness indicators. Developmental Psychology. 2010a; 46(5): 1008-1017.

Grissmer D, Grimm KJ, Aiyer SM, Murrah WM, Steele JS. New school readiness indicators. Charlottesville: University of Virginia, Center for Advanced Study of Teaching and Learning; 2010b. (Research brief).

Hart B, Risley TR. Meaningful differences in the everyday experience of young American children. Baltimore, MD: Paul H. Brookes Publishing Co.; 1995.

Heckman JJ, Pinto R, Savelyev P. Understanding the mechanisms through which an influential early childhood program boosted adult outcomes. American Economic Review. 2013; 103(6): 2052-2086.

Howse RB, Calkins SD, Anastopoulos AD, Keane SP, Shelton TL. Regulatory contributors to children's kindergarten achievement. Early Education and Development. 2003b; 14(1): 101-120.

IOM and NRC (National Research Council). Preventing mental, emotional, and behavioral disorders among young people: Progress and possibilities. Washington, DC: The National Academies Press; 2009.

La Paro KM, Pianta RC. Predicting children's competence in the early school years: A meta-analytic review. Review of Educational Research. 2000;70(4):443484.

Leckman JF, March JS. Editorial: Developmental neuroscience comes of age. Journal of Child Psychology and Psychiatry. 2011; 52(4): 333-338.

Leerkes EM, Paradise MJ, O'Brien M, Calkins SD, Lange G. Emotion and cognition processes in preschool children. MerrillPalmer Quarterly. 2008; 54(1):102-124.

Miller AL, Seifer R, Stroud L, Sheinkopf SJ, Dickstein S. Biobehavioral indices of emotion regulation relate to school attitudes, motivation, and behavior problems in a low-income preschool sample. Annals of the New York Academy of Sciences. 2006; 1094: 325329.

Pagani L, Messier S. Links between motor skills and indicators of school readiness at kindergarten entry in urban disadvantaged children. Journal of Educational and Developmental Psychology. 2012; 2(1): 95.

Sandler AD, Watson TE, Footo M, Levine MD, Coleman WL, Hooper SR. Neurodevelopmental study of writing disorders in middle childhood. Journal of Developmental and Behavioral Pediatrics. 1992; 13(1): 17-23.

Zimmerman E, Woolf SH. Understanding the relationship between education and health. 2014. [March 23, 2015]. (Discussion paper). http://www.iom.edu/understandingtherel ationship.

\section{How to cite this article:}

Kavitha Kiran, V. and Yashoda, K. 2020. Developmental Assessment Status of Young Children in Agrarian Families of Telangana State, India. Int.J.Curr.Microbiol.App.Sci. 9(09): 384-390. doi: https://doi.org/10.20546/ijcmas.2020.909.048 